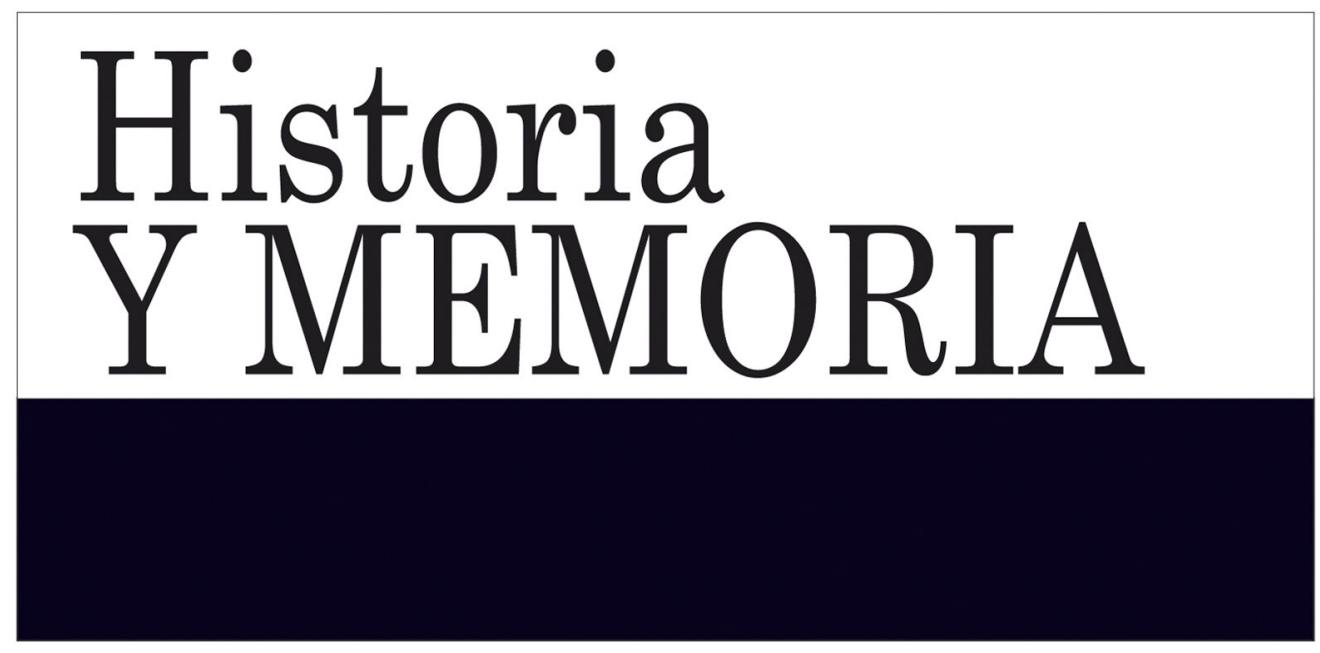

ISSN: 2027-5137 Julio - Diciembre, Año 2014 - Tunja, Colombia

\title{
Provivienda: protagonista de la colonización popular en Colombia
}

Maria Elvira Naranjo Botero Páginas: 89 - 118

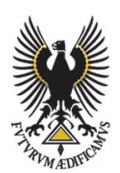




\title{
Provivienda: protagonista de la colonización popular en Colombia*
}

\author{
María Elvira Naranjo Botero ${ }^{1}$ \\ Universidad Nacional de Colombia
}

Recepción: 18/12/2013

Evaluación: 30/01/2014

Aprobación: 01/04/2014

Artículo de Investigación e Innovación.

\section{Resumen}

Este artículo reconstruye la historia de Provivienda, a partir del concepto de colonización popular, e interpreta su dinámica organizativa a través tanto de entrevistas a sobrevivientes fundadores de los barrios de invasión como de los documentos del archivo de la organización. Creada en 1959, Provivienda es la primera organización social de destechados, aún vigente e integrada por desplazados forzados que buscaron refugio y obtuvieron vivienda propia mediante acciones colectivas. Muchos de sus protagonistas, que fundaron fincas cafeteras adquiridas ocupando baldíos, fueron despojados por la violencia de los años 50, colonizaron posteriormente ejidos y terrenos municipales en centros poblados, e hicieron parte de la Unión Patriótica. En la actualidad, Provivienda organiza a los destechados en un movimiento de inquilinos, para su plena inclusión como ciudadanos con derecho a vivienda digna. Una reflexión sobre este proceso histórico en la perspectiva actual

\footnotetext{
* Este artículo es producto del avance de tesis del Doctorado en Estudios Políticos y Relaciones Internacionales, financiado por la Universidad Nacional de Colombia.

1 Socióloga y Candidata a Doctora en Estudios Políticos y Relaciones Internacionales, Universidad Nacional de Colombia. Profesora asociada, Universidad Nacional de Colombia. Grupo de investigación: Grupos de investigación del IEPRIUNAL: Actores armados, conflicto y DIH. Democracia, nación y guerra. Líneas de investigación: Acciones colectivas, resistencia civil, conflicto armado. menaranjob@ unal.edu.co
} 
de negociación política entre la insurgencia y el gobierno puede ser un aporte a la comprensión de las causas del conflicto y a la construcción de una paz con justicia social.

Palabras clave: Colonización popular, vivienda por autoconstrucción, desplazamiento forzado.

\section{Provivienda: A Factor in the Squatter Colonization of Colombia}

\section{Summary}

This article reconstructs the history of Provivienda, with regards to the concept of squatter colonization, and interprets Provivienda's organizational structure through interviews with surviving founders of these squatter shantytowns as well as through documents from the archives of the organization. Created in 1959 and still operating, Provivienda was the first social organization of homeless individuals, consisting of victims of forced displacement that sought shelter and obtained their own housing through collective action. Many of its founders, who started coffee farms by squatting on public land, had been dispossessed by the violence of the 1950's. They later squatted on public lands and vacant municipal properties in population centers and formed part of the Patriotic Union political party. Currently, Provivienda organizes homeless individuals into a movement of tenants and advocates for their full inclusion as citizens with the right to a decent home. A reflection on this historical process from the view of current political negotiation between insurgent groups and the government may contribute to the understanding of the causes of the national conflict and to the building of peace with social justice.

Key words: squatter colonization, self construction, forced displacement. 


\section{Provivienda: protagoniste de la colonisation populaire en Colombie}

\section{Résumé}

Cet article reconstruit l'histoire de Provivienda à partir du concept de colonisation populaire et étudie sa dynamique organisationnelle par l'intermédiaire d'entretiens aux survivants fondateurs des quartiers d'invasion ainsi que des documents des archives de l'organisation. Créée en 1959, Provivienda fut la première organisation de sans-toit, encore en vie et constituée de déplacés forcés ayant cherché refuge et obtenu un logement pour eux au moyen d'actions collectives. Beaucoup de ses protagonistes, qui ont fondé des exploitations caféières acquises en occupant des terres en friche, ont été dépouillés par la violence des années 50 , et ont ensuite colonisé des ejidos et des terrains municipaux, ont milité $\mathrm{au}$ sein de l'Union Patriotique. Actuellement Provivienda organise les sans-toit dans un mouvement de locataires, afin de chercher leur pleine inclusion comme citoyens ayant droit à un logement digne. Une réflexion sur ce processus historique dans la perspective actuelle d'une négociation politique entre les guérillas et le gouvernement peut aider à la compréhension des causes du conflit et à la construction d'une paix avec justice sociale.

Mots clés: colonisation populaire, logement par autoconstruction, déplacement forcé.

\section{Introducción}

En este artículo se presenta una historia de los fundadores de Provivienda, víctimas de la violencia bipartidista de los años 50, que lograron consolidar sus barrios y ser propietarios de sus viviendas gracias a su experiencia previa como colonizadores rurales organizados. Se menciona en primer lugar, el contexto violento de la colonización rural de donde proceden los protagonistas de este relato; en segundo lugar, se describe cómo a partir del desplazamiento forzado, se 
inicia y se consolida el proceso de colonización urbana; y por último se presenta una síntesis de los principales períodos históricos de la organización desde 1959 hasta el año 2005. La Central Nacional Provivienda fundada en 1959 es la primera organización social de destechados creada en Colombia y es la única en América Latina que ha permanecido en funcionamiento por más de 50 años.

En relación con la metodología utilizada en la investigación, debe señalarse que se asumió una perspectiva de pluralismo metodológico, se combinaron técnicas convencionales con herramientas de Investigación Acción Participativa- IAP, ejercicios de cartografía social, conversatorios y debate con los protagonistas para comparar y complementar los hallazgos documentales con las memorias de los fundadores de la organización. A partir de los relatos obtenidos, ha sido posible reconstruir las circunstancias y los hechos vividos por los colonizadores populares rurales y urbanos de Provivienda.

Con cerca de 80 entrevistas a los sobrevivientes fundadores de barrios en 10 ciudades, se ha intentado comprender los repertorios de contestación que han caracterizado estas acciones colectivas a lo largo de su historia. A través del proceso de la IAP ha sido posible crear un espacio de confianza con los fundadores sobrevivientes y con quienes actualmente hacen parte de la organización, además de tener acceso a cerca de 2000 documentos conservados en bodega durante 4 décadas. Lo documentos de Provivienda son en su mayoría de carácter administrativo, financiero y contable, correspondencia, actas, escrituras, planos, etc. En ninguno de ellos ni en las entrevistas a los fundadores se encontró evidencia de vínculos con las FARC u otras organizaciones armadas.

Con estos documentos se realizó un proceso de organización y clasificación documental, creando así su archivo histórico que hoy proporciona información pertinente para reconstruir la memoria de la organización, ubicar nombres, fechas, lugares y cobertura de las acciones 
colectivas emprendidas por los viviendistas. La organización de este archivo fue esencial para encontrar evidencias de que existieron cerca de 500 barrios de Provivienda en 120 municipios, ${ }^{2}$ como también para comprender las estrategias pedagógicas y organizativas, la estructura y funcionamiento de sus barrios y para ubicar a muchos de los fundadores, quienes posteriormente fueron entrevistados.

\section{La colonización popular rural}

En la primera mitad del siglo XX, muchos campesinos sin tierra migraron hacia las vertientes de la cordillera central de Colombia, en busca de tierras baldías. La existencia de grandes cantidades de tierra no titulada en las laderas fue decisiva para el nacimiento de fincas pequeñas y medianas en el corazón de la zona cafetera del país. Así lo evidencia el primer censo oficial realizado en 1932, que registró 15000 fincas cafeteras, la mayoría de ellas con menos de 10 hectáreas. Esta producción en pequeñas propiedades fue importante para el desarrollo económico del país y para la estabilidad de la política colombiana en los albores del siglo $\mathrm{XX}^{3}$. Sin embargo, su legitimidad y función estabilizadora se rompen con la llamada violencia bipartidista.

2 Provivienda, Archivo Histórico, Los 120 municipios con Centros de Provivienda son: Agua de Dios, Algeciras, Apartadó, Apulo, Arauquita, Armenia, Armero, Ayapel, Barranquilla, Barrancabermeja, Bello, Bogotá, Bosa, Bucaramanga, Buenaventura, Cali, Campoalegre, Candelaria, Carepa, Cartagena, Castilla, Ciénaga, Circasia, Consacá, Córdoba, Corinto, Coyaima, Cúcuta, Chaparral, Chía, Chigorodó, Chinchiná, Doncello, Dosquebradas, El Banco, El Castillo, El Espinal, El Playón, Facatativá, Flandes, Florencia, Fontibón, Fusagasugá, Girardot, Granada, Honda, Ibagué, Ipiales, Jamundí, La Dorada, La Mesa, La Montañita, La Plata, La Virginia, La Unión, La Uribe, Lejanías, Machado, Madrid, Manizales, Mariquita, Medellín, Mesetas, Mesitas del Colegio, Miranda, Montenegro, Montería, Montañita, Natagaima, Neiva, Necoclí, Obando, Ocaña, Paipa, Palestina, Palmira, Pasca, Pasto, Pereira, Piedecuesta Piñalito, Pitalito, Popayán, Pradera, Puerto Asís, Puerto Boyacá, Puerto Colombia, Puerto López, Puerto Salgar, Puerto Wilches, Remedios, Rionegro, Rivera, San Alberto, San Carlos, San Pablo, Santa Marta, Santa Rosa de Cabal, Saravena, Segovia, Sevilla, Sincelejo, Sibaté, Soacha, Sogamoso, Tabio, Tulúa, Túquerres, Turbo, Valledupar, Valparaíso, Villavicencio, Villa del Rosario Viotá, Yacopí, Yumbo y Zipaquirá.

3 Charles Bergquist, Café y conflicto en Colombia, 1886-1910 (Medellín: FAES, 1981), 304 . 
La consolidación de nuevas zonas productivas, motivó a presiones violentas de especuladores y terratenientes usurpadores que se ocultaron detrás de supuestas razones políticas durante este período. Las grandes compañías agrícolas capitalistas y los futuros hacendados buscaron los mecanismos para apoderarse legalmente de las parcelas de los colonizadores desterrados. Esta violencia puede considerarse una larga guerra agraria de los latifundistas que, en el marco de políticas estatales de concesiones territoriales, intentaron despojar y desalojar a los colonos pioneros de las laderas vírgenes que habían valorizado con su trabajo. En algunas ocasiones, estos terratenientes recibieron, incluso, la titulación de estos baldíos. Rocío Londoño afirma que en el Tolima esta violencia despojó de sus tierras al 48\% de los campesinos ${ }^{4}$; por su parte, Aprile Gniset ${ }^{5}$ afirma que las migraciones campo-ciudad, eran en realidad éxodos masivos, forzados y prolongados, que se desarrollaban en circunstancias bélicas por expulsión y destierro. Situaciones en donde repercutieron las condiciones políticas y sociales generadas en el Estado de Sitio decretado por el gobierno nacional después del Bogotazo.

En las entrevistas realizadas a los fundadores de los barrios de Provivienda fue posible obtener testimonios que evidencian la intensidad del drama que vivieron las víctimas de esta violencia: "Los liberales perseguidos por los chulavitas en el norte del Valle del Cauca huían hacia Cali. Allí a las orillas del río Cauca llegaban centenares de refugiados en condiciones de miseria absoluta, con el doctor Alirio Caicedo atendíamos a los heridos y a los enfermos"6.

En febrero de 1953, comisiones del ejército en la vereda del Palmar quemaron las casas y asesinaron a los vecinos en el camino [...] entonces, con 38 ó 40 guerrilleros y con las familias que eran más de 4.000 personas (hombres, mujeres,

\footnotetext{
4 Rocío Londoño, Juan de la Cruz Varela. Sociedad y política en Sumapaz (Bogotá: FCH, 2012), 486.

5 Jacques Aprile-Gniset, "Memorias del destierro y del exilio", en: Cátedra Jorge Eliécer Gaitán (Bogotá: Universidad Nacional, 2007): 142.

6 Entrevista a Cruz, Celmira, dirigente comunista de Chaparral, nacida en 1930. Cali, 5 de julio de 2011.
} 
niños y ancianos) salimos por la cordillera de Altamizal, arriba de Villarrica [...] por el páramo de Sumapaz y salimos hacia el Guayabero y hacia el Duda. ${ }^{7}$

En 1950, cuando llegué como inspector de educación a Ataco (Tolima) había una lista de niños que tenían prohibida la entrada a la escuela porque eran hijos de comunistas y de evangélicos. En Santiago Pérez (Tolima) había una comunidad evangélica y tenían una capilla en Campohermoso. Eran evangélicos y gaitanistas. Ellos fueron masacrados por la policía que les cortaba la cabeza y les quemaba las casas. El padre Grisales, en la iglesia católica de Ataco les daba la comunión a los asesinos y los bendecía con agua bendita, cuando iban a matar a los evangélicos. ${ }^{8}$

Frente a este drama, se observa que las zonas rurales expulsoras son las de mayor prosperidad cafetera. La persecución política obliga al abandono de las pequeñas fincas cafeteras ubicadas en las vertientes de las cordilleras de Cundinamarca, Tolima, Eje cafetero y norte del Valle. Así lo evidencian los campesinos inmigrantes: "Teníamos una finca cafetera en el Tolima y después del 9 de abril tuvimos que huir amenazados porque éramos liberales. Dejamos todo lo que teníamos y nos vinimos a Bogotá". Otros pobladores de asentamientos populares surgidos en Bogotá se expresan de manera similar: "Vivíamos en una finca cerca de Armenia, pero sucedió que mataron a mis hermanos y nuestra casa fue atacada varias veces, por lo cual mi marido se vino a Bogotá a buscar trabajo y luego nos vinimos con la familia"9. Una historia similar es descrita por un fundador del barrio Policarpa Salavarrieta en Bogotá:

Nuestra finca era cafetera, en el año 1949, nosotros tuvimos que salir huyendo por los cafetales porque en la volqueta del municipio de Rovira, venía una comisión de la policía a incendiar todo. Venían de San Antonio de los Micos, una vereda más arriba de Roncesvalles [...] en esa vereda

7 Jacques Aprile-Gniset, La crónica de Villarrica (Bogotá: Ediciones Ilsa, 1991). 78.

8 Entrevista a Dorado, Jesús María, maestro del Cauca, nacido en 1920. Bogotá, 10 de febrero de 2013.

9 Alfonso Torres, La ciudad en la sombra (Bogotá, Cinep, 1993), 43 y 44. 
mataron a más de 80 personas. Por eso nos fuimos y nunca volvimos por allá. ${ }^{10}$

Estos hechos también se evidencian a través de algunas entrevistas realizadas a los fundadores de barrios de Provivienda en Soacha y en Valledupar que llegaron allí procedentes de zonas cafeteras de Cundinamarca y Norte de Santander, expulsados por la violencia liberal-conservadora:

En plena violencia liberal conservadora mi papá murió. Mi mamá y yo tuvimos que abandonar la finca y huir con mi abuelita y sus hijos hacia Honda porque allí se brindaba protección a los desplazados de muchos lugares de Cundinamarca y Tolima. Llegó tanta gente buscando refugio que la situación en Honda se hizo muy difícil. ${ }^{11}$

Yo nací en la zona cafetera, en Montenegro (Quindío), un pueblo liberal. Mi papá era gaitanista. En la Plaza de Bolívar de Pereira recuerdo que asistí a una manifestación con la plaza llena de gente y desde un balcón hablaba Jorge Eliécer Gaitán, allí lo conocí. ${ }^{12}$

Soy un hombre que vengo de familias campesinas. Nací en el Carmen (Norte de Santander) una pequeña población cafetera en las estribaciones de la cordillera oriental. $\mathrm{Mi}$ abuelo fue combatiente en la guerra de los Mil días. Vivimos una violencia permanente contra los liberales en el Carmen. A raíz de la muerte de Gaitán teníamos que vivir huyendo y esta violencia se incitaba desde el púlpito de la Iglesia. ${ }^{13}$

Ya no se podía ni dormir en la casa. Cada día nos tocaba, a las seis de la tarde, acomodar las cobijitas por ahí y escondernos en el monte o debajo de las matas de café. Nadie podía quedarse en la casa. En la mañana primero debíamos asegurar que no había nadie para regresar a la casa. Y eso duró harto tiempo. ${ }^{14}$

10 Jacques Aprile-Gniset, La crónica...29.

11 Entrevista a Borray, Anita, fundadora del barrio Primero de Mayo en Valledupar, nacida en Cundinamarca en 1935. Valledupar, 7 de enero de 2011.

12 Entrevista a Upegui, Mario, Concejal de Bogotá. Bogotá, 2 de octubre de 2011.

13 Entrevista a Quintero, Guzmán, Barrio Fundadores de Valledupar. Valledupar, 10 de enero de 2011.

14 Jacques Aprile-Gniset. La crónica...39. 


\section{La colonización popular urbana}

El éxodo rural masivo de los años cuarenta y cincuenta obligó a la mayoría de los migrantes campesinos a sobrevivir en las ciudades como trabajadores por cuenta propia, en oficios artesanales o como vendedores ambulantes ${ }^{15}$. Son en su mayoría, campesinos y campesinas, "toderos", expertos en trabajos manuales, maestros de obras, albañiles, plomeros, electricistas, carpinteros, modistas, cocineras, lavanderas, sastres, sombrereros, zapateros, barberos y joyeros. Son quienes saben cómo y dónde solucionar los problemas cotidianos, hacer reparaciones, trámites y reclamaciones. A través de su organización social lograron conseguir vivienda para cerca de medio millón de destechados. Los dirigentes de Provivienda son militantes comunistas destechados e invasores, que en la ciudad se vinculan, en su gran mayoría, al sector informal de la economía como trabajadores por cuenta propia ${ }^{16}$.

Torres observa que, en general, fue escasa la vinculación de los bogotanos a la industria fabril capitalista y lo corrobora en el poco número de obreros en los asentamientos populares. Algunos pobladores fundadores de barrios surgidos a fines de la década del 50 narran que:

Había muchos albañiles, carpinteros y zapateros, algunos trabajaban en plazas de mercado [...] éramos más que todo trabajadores independientes, ornamentadores, vendedores ambulantes y celadores [...] vendiendo chance o promociones puerta a puerta; otros le jalamos a lo que salga, plomería, construcción o pintura. ${ }^{17}$

A partir de una encuesta realizada en 1965 a los jefes de familia de barrios llamados "subnormales", el sociólogo Eduardo Ramos pudo constatar que más del 70\% trabajan en actividades informales, como puede observarse a continuación:

15 Aún en 2013, la mayoría de la población colombiana está ocupada o sub-ocupada en el sector informal de la economía en actividades, que en términos coloquiales se denominan "el rebusque".

16 Nicolás Buenaventura. Qué pasó camarada? (Bogotá: Apertura, 1992), 67.

17 Alfonso Torres. La ciudad...47-51. 
Cuadro 1. Distribución porcentual de los padres de familia de barrios subnormales según ocupación. Bogotá, 1965.

\begin{tabular}{|l|c|}
\hline \multicolumn{1}{|c|}{ Ocupación de jefes de familia } & Porcentajes \\
\hline Obreros de la construcción & $22.8 \%$ \\
\hline Agricultores & $17.4 \%$ \\
\hline Artesanos independientes & $17.4 \%$ \\
\hline Vendedores ambulantes & $13.0 \%$ \\
\hline Empleados almacenes y oficinas & $12.0 \%$ \\
\hline Empleados en oficios domésticos & $6.6 \%$ \\
\hline Obreros fabriles & $5.4 \%$ \\
\hline Desempleados & $5.4 \%$ \\
\hline Total & $100 \%$ \\
\hline
\end{tabular}

Fuente: Eduardo Ramos, Aspectos sociales de la inmigración en Bogotá (Universidad Nacional, 1965).

Para seguir el rastro de los destechados invasores, que es el caso que nos ocupa, es imprescindible tomar como referencia los desarrollos conceptuales de Jacques Aprile. De acuerdo con este autor, los nuevos pobladores pasan de colonizar tierras baldías de la nación a la colonización de los ejidos y los predios municipales. Así, se puede establecer una nueva categoría territorial histórica de la urbanización: la colonización popular urbana ${ }^{18}$.

La colonización popular urbana se constituyó como un rasgo característico de la fase moderna de la urbanización, cuyo proceso es explicado por Lina Sánchez:

[...] las tierras que circundaban al poblado, se integran a la urbe moderna por medio de un verdadero proceso de colonización urbana popular, en el cual se observan muchos rasgos típicos de la colonización agraria del período anterior [...] se puede afirmar que la urbe colombiana nueva, en gran parte, es producto de los colonos destechados. "Invasiones",

18 Jacques Aprile-Gniset, La ciudad colombiana (Bogotá: Banco Popular, 1992), 622-625. 
"tomas" y "ocupaciones" deben ser analizadas como uno de los elementos que integran el proceso de urbanización nacional. ${ }^{19}$

Los viviendistas de la segunda mitad del siglo XX son bastante heterogéneos. Hay desde invasores espontáneos que individualmente buscaron un techo en donde refugiarse hasta iniciativas de urbanizadores piratas ligados al clientelismo tradicional. También se encuentran las acciones colectivas directas que protagonizaron los destechados pertenecientes a una organización social, que fundaron barrios de invasión, como es el caso de la Central Nacional Provivienda.

Con un movimiento social silencioso, nacen cientos de nuevos barrios clandestinos, en condiciones de miseria, carentes de servicios básicos esenciales. La vivienda es para los campesinos migrantes no solo un techo, la parcela familiar proporciona el alimento y es la base de la organización social. La importancia de conseguir tierra es un rasgo cultural característico de quienes han sido despojados en el campo, ya que representa seguridad para sus familias y la perspectiva de emprender con otros una nueva vida barrial superando el desarraigo. Como lo describen las crónicas de los viviendistas, la inmensa mayoría de quienes participan en la lucha por la vivienda son mujeres y niños ${ }^{20}$.

Alfonso Torres Carrillo relaciona cerca de 250 acciones colectivas emprendidas por colonizadores populares urbanos entre 1958 y 1971, para solucionar su problema habitacional en barrios de Bogotá. Estos habitantes realizaron acciones colectivas de diversa índole como movilizaciones, marchas, bloqueo de vías, pedreas, resistencia al desalojo, reclamaciones escritas, memoriales a las autoridades, recolección de fondos en bazares, festivales, mingas y trabajos colectivos de autoconstrucción.

19 Lina Sánchez, "Migración forzada y urbanización en Colombia", en: Procesos Urbanos Informales (Bogotá: Universidad Nacional, 2007): 13.

20 Alfonso Torres, La ciudad...98. 
Los conflictos con las autoridades se ubican principalmente en los barrios de Usme, Yomasa, Santa Librada, Los Laches, Suba, Engativá, Soacha, Lucero, Juan XXIII, Salvador Allende, Camilo Torres, El Pedregal, La Casona y El Vergel. Durante el mismo período, las invasiones de terrenos que pueden considerarse más significativas en la capital ocurren en: Las Colinas, Policarpa, Juan XXIII, Santa Rosa, El Dorado, El Quindío, El Progreso, Salvador Allende, Atahualpa, Camilo Torres, Los Olivos y Nuevo Chile ${ }^{21}$.

Ahora bien, este proceso de colonización popular urbana se realizó fundamentalmente por autoconstrucción. Su magnitud es tan significativa que llegó a constituir más del $50 \%$ de las viviendas urbanas construidas durante este período, como puede comprobarse en las diferentes formas de producción de vivienda tipificadas y cuantificadas por Samuel Jaramillo para la ciudad de Bogotá. Desde 1938 hasta 1985 los más pobres, que representan cerca de la mitad de la población, resolvieron su necesidad de vivienda acudiendo a la autoconstrucción, la cual se encuentra ligada a la ocupación ilegal del espacio ${ }^{22}$. En la práctica, esta modalidad se convirtió en la alternativa de vivienda más utilizada por amplios sectores populares, como puede observarse en el cuadro que se presenta a continuación.

Cuadro 2. Distribución porcentual de las formas de producción de vivienda por períodos en Bogotá (1938-1985). \% sobre el total de viviendas.

\begin{tabular}{|c|c|c|c|c|}
\hline $\begin{array}{c}\text { Formas de } \\
\text { producción } \\
\text { según } \\
\text { períodos }\end{array}$ & $\begin{array}{c}\text { Promoción } \\
\text { capitalista }\end{array}$ & $\begin{array}{c}\text { Por } \\
\text { encargo }\end{array}$ & $\begin{array}{c}\text { Estatal } \\
\text { subsidiada }\end{array}$ & $\begin{array}{c}\text { Auto- } \\
\text { construcción }\end{array}$ \\
\hline $1938-51$ & 23.3 & 16.9 & 4.6 & 55.2 \\
$1951-64$ & 23.8 & 17.3 & 16.8 & 42.1 \\
$1964-73$ & 16.0 & 12.9 & 21.2 & 49.9 \\
$1973-85$ & 31.8 & 15.0 & 19.5 & 49.9 \\
\hline
\end{tabular}

Fuente: Samuel Jaramillo, La vivienda en Bogotá (CEDE, 1992).

21 Alfonso Torres, La ciudad...208.

22 Samuel Jaramillo, Organización popular y desarrollo urbano (Bogotá: U. Externado, 1997), 54. 


\section{Los colonizadores populares urbanos que dan origen a Provivienda}

La creación y consolidación de la Central Nacional Provivienda en Bogotá durante 1959 fue posible debido a las acciones colectivas que se emprendieron en Cali, una década antes, en los terrenos ejidales. Allí el problema habitacional tuvo dimensiones cada vez mayores, como consecuencia del crecimiento poblacional causado por las grandes migraciones campesinas que llegaban a la ciudad huyendo de la violencia rural. Entre los años 1942 y 1946, miles de destechados intentaban ocupar los terrenos donde hoy existen los barrios de Agua Blanca y Terrón Colorado, en la capital del Valle del Cauca. Como relata el escritor Arango Zuluaga ${ }^{23}$, estas acciones eran fundamentalmente espontáneas y con permanentes enfrentamientos entre ocupantes y autoridades. Después de cada desalojo los invasores intentaban nuevamente ocupar los mismos terrenos y otra vez las autoridades desalojaban. Las orillas del río Cali hacia el norte y del río Cauca hacia el oriente fueron pobladas por miles de familias. Algunas de ellas habían ocupado directamente y otras se encontraban en calidad de inquilinas de algunos individuos que, sin tener necesidad de vivienda, participaban de las invasiones para apoderarse de lotes que luego alquilaban a familias sin techo. La mayoría de las veces, con la complicidad de las autoridades que veían una oportunidad de adueñarse de las propiedades ejidales para su enriquecimiento personal. Cuando las familias se atrasaban en el pago del arrendamiento, las autoridades hacían el desalojo.

Julio Rincón y Alfonso Barberena se oponían a esta clase de atropellos. Así en una ocasión, evitaron un desalojo de 100 familias. El personero municipal de entonces, Alfonso Barberena, se presentó en compañía de Julio Rincón, cuando el juez se disponía a firmar la orden de desalojo; Barberena mostró documentos que probaban que los terrenos eran de propiedad ejidal y que quienes figuraban como arrendadores

23 Carlos Arango Zuluaga, La lucha por la vivienda en Colombia (Bogotá: Ecoe, 1985), 20-22. 
incurrían en un fraude. De esa manera las familias se salvaron de ser desalojadas recibiendo posteriormente, adjudicación legal de los terrenos por parte del municipio. Alfonso Barberena era un dirigente liberal. Como concejal logró la legalización de las ocupaciones que dieron vida a los barrios Nacional y Primero de Mayo. Cuando fue personero municipal de Cali realizó acciones decididas de apoyo a los destechados, y cuando se desempeñó como congresista logró la aprobación de la Ley 41 de 1948, también conocida como Ley Barberena sobre los terrenos ejidales, por la cual se estableció la imprescriptibilidad de los ejidos o tierras comunales alrededor de los centros urbanos ${ }^{24}$.

La idea de organizar a los destechados para resistir a los desalojos y conseguir vivienda propia fue una iniciativa de Barberena y Rincón, ante la magnitud del drama que vivían tantas familias ${ }^{25}$. De común acuerdo, emprendieron juntos durante varios años la defensa de quienes no tenían vivienda y lograron obtenerla para cientos de pobladores. Rincón y Barberena combinaban la actividad normativa y jurídica con las acciones directas. Preferían que la tierra fuera entregada a los nuevos pobladores, a través del Concejo o mediante los mecanismos jurídicos, pero cuando las mayorías oficialistas lo impedían, entonces apoyaban a los destechados para que ocuparan directamente. En síntesis, de alguna manera puede decirse que desde sus inicios, la lucha por la vivienda se hizo con una "combinación de las formas de lucha". Las familias ocupaban los terrenos y a la vez estaban llenando formularios para que la entidad oficial indicada les adjudicara el lote ocupado. No era difícil de lograr si comprobaban que la familia no tenía vivienda. Así, amparándose en las leyes vigentes de la época sobre los ejidos, podían ocupar también en algunos casos predios privados de origen ejidal.

24 Fernando Urrea y Fernando Murillo, "Dinámica del poblamiento y algunas características de los asentamientos populares con población afrocolombiana en el oriente de Cali". Ponencia presentada al Observatorio Socio-político y Cultural sobre Desplazados, migraciones internas y reestructuraciones territoriales. (Bogotá: FCH Universidad Nacional de Colombia, 1999):15.

25 Entrevista a Jerez, Luis, presidente nacional de Provivienda en 2012. Bogotá, 20 de febrero de 2012. 
En el año de 1946 los comités Provivienda que existían en Cali acordaron constituirse en una Federación con el fin de afrontar unidos la represión policial en las ocupaciones. A la reunión constitutiva asistieron delegados de 40 comités nombrando una junta directiva integrada, entre otros, por Luis Morales y Pedro Salas, militantes comunistas que posteriormente participarían en la fundación de la Central Nacional Provivienda y del barrio Policarpa Salavarrieta en Bogotá ${ }^{26}$. La Federación funcionó durante dos años y se desintegró a raíz de la violencia desatada con el asesinato de Jorge Eliécer Gaitán y de Julio Rincón que también murió asesinado el 8 de junio de 1951. En esos días se discutía en el Concejo de Cali un proyecto de acuerdo de su autoría, para expropiar los terrenos ejidales que estaban en posesión de familias pertenecientes a la élite vallecaucana. Su cuerpo fue hallado con graves huellas de tortura, que le ocasionaron la muerte junto con el veneno que le obligaron a ingerir.

Los años cuarenta y cincuenta fueron una época de mucha agitación social en varias ciudades colombianas. A finales de la década del 50, se iniciaron también comités locales de Provivienda promovidos por los sindicatos de oficios varios, de artesanos y trabajadores independientes y que contaron con la participación activa de militantes comunistas como Carlos Herrera, Camilo Larrazábal, Carlos Arias, Tulio Villa, Vicente Martínez y Anita Borray. En Ciénaga invadieron los ejidos conocidos como playones para conformar los barrios Jorge Eliécer Gaitán y Nueva Colombia y en Valledupar los terrenos municipales de la Granja Ganadera dando origen al barrio Primero de Mayo ${ }^{27}$. Las experiencias de los primeros comités de Provivienda en Cali, Ciénaga, Valledupar, Ibagué y otras ciudades del país, hicieron posible la creación de una organización nacional que integrara estas iniciativas para darles una mayor proyección y cobertura en todo el territorio nacional.

26 Carlos Arango Zuluaga, La lucha por la vivienda...22.

27 Entrevista a Martínez, Vicente, sindicalista fundador del barrio Primero de Mayo en Valledupar. Valledupar, Enero 25 de 2011. 
El 16 de febrero de 1959 se llevó a cabo la primera reunión de la Central Nacional Provivienda, evento convocado por el Partido Comunista e impulsado por Alfonso Barberena. Su propósito era promover y coordinar, en todo el país, las acciones colectivas de los destechados, orientadas a obtener soluciones de vivienda popular urbana ${ }^{28}$. Contó con la participación de sindicalistas y abogados como Hernando Garavito Muñoz, quien redactó el proyecto de Estatutos de la nueva organización y tramitó la personería jurídica que sería obtenida el 5 de mayo de 1961 mediante resolución del Ministerio de Justicia. Como narra Arango Zuluaga:

Fue la organización pionera de las luchas de los destechados, en la segunda mitad del siglo XX; concibió y dirigió muchas de las ocupaciones de hecho más notables que dieron lugar a un nuevo tipo de barrios caracterizados por la organización de sus habitantes, las prácticas colectivas de construcción, equipamiento urbano y seguridad y una activa participación en las protestas sociales y políticas de otros sectores sociales. ${ }^{29}$

A continuación se presenta una síntesis de los principales períodos históricos de la organización desde 1959 hasta el año 2005.

\section{- Primer período de Provivienda (1959-1971)}

En este período, predominan las ocupaciones a terrenos ociosos, que con frecuencia eran ejidos o predios municipales y otras veces baldíos de propiedad incierta. El proceso organizativo se inicia a partir de las necesidades apremiantes de la mayoría de los destechados, pues habían huido de sus sitios de origen hacia las ciudades en condiciones precarias y con la urgencia de encontrar un techo vivían hacinados en inquilinatos miserables ${ }^{30}$. Ante esta problemática, algunos militantes del Partido Comunista crearon los Centros de Inquilinos de

28 Provivienda, Informe a la III Asamblea Nacional (Bogotá: Archivo Histórico Cenaprov, 1963).

29 Carlos Arango Zuluaga, La lucha por la vivienda...28.

30 Provivienda, Informe a la V Asamblea Nacional (Bogotá: Archivo Histórico Cenaprov, 1967), 2. 
Provivienda. El centro tenía como labor brindar a los socios formación política en los principios y objetivos de Provivienda, educación sobre el problema de la vivienda, sus soluciones, y capacitación para participar en las acciones colectivas de ocupación de predios. Estos centros tenían también la tarea de encontrar predios cercanos a las ciudades en donde se pudieran ubicar las familias que no tenían vivienda y promover la afiliación de inquilinos. Según informe a la V Asamblea, un Centro de Inquilinos llegó a tener más de tres mil afiliados ${ }^{31}$.

Cada vez que un Centro de Inquilinos decidían ocupar un lote, se elaboraba un plan detallado con los futuros ocupantes, quienes además de tener ensamblada su caseta y aforados sus enseres domésticos, debían cumplir todas y cada una de las pautas acordadas. Para las invasiones masivas, estudiaban previamente el terreno, distribuían y numeraban en un plano los lotes, se trazaban planos para levantar las casetas distanciadas unas de otras con el fin de asignar a cada familia un lote de buen tamaño y abarcar la mayor extensión posible de terreno. Las casetas fabricadas se numeraban de acuerdo al plano e invadían todos al tiempo, con un operativo relámpago, sincronizado y muy eficaz ${ }^{32}$. Así, estas acciones colectivas se realizaban casi con la precisión de un operativo militar. En los centros se estableció un reglamento según el cual todo aquel que llegara a solicitar un lote tenía que llegar con su familia y sus equipajes el día de la mudanza, con el fin de impedir que llegaran personas que no necesitaban vivir allí. De esta manera, en las acciones colectivas de tomas de predios, participaron activamente y jugaron un papel protagónico las mujeres y los niños.

Batiéndose contra el frío, el sol abrasador, la lluvia, el barro, los policías y el hambre. Ganan y pierden batallas de aguaceros, inundaciones, enfermedades, palos y balas. Se niegan a sucumbir. Luchan con las leyes y contra las leyes, y se arrojan al mismo lugar de donde han sido arrojados. El

31 Provivienda, Informe a la V Asamblea...11.

32 Una estrategia que hacía prácticamente imposible para las autoridades locales controlar la invasión ante el hecho de que por la noche había cierta cantidad de casetas y por la mañana aparecía otra cantidad muy superior. 
drama empieza por lo general en las altas horas de la noche, mientras las ciudades duermen. A la mañana siguiente, la ciudad ha crecido unos cuantos metros. ${ }^{33}$

Los trasteos solo llegaban en carro hasta una distancia prudente y de allí en adelante eran transportados al hombro. Cerca de los barrios recién ocupados, la policía intentaba impedir el transporte de elementos que sirvieran para construir casetas, requisaba a los transeúntes y detenía a los choferes sorprendidos entregando estos elementos. De allí que las vecinas optaran por descargar colectivamente los materiales y proteger al chofer, al ayudante y al carro. Después de cada desalojo los (y las) invasoras intentaban ocupar los mismos terrenos y de nuevo eran desalojadas. Así ocurrió en sucesivas ocasiones, muchas veces desistieron y otras perseveraron hasta lograr realizar su sueño y obtener su vivienda.

Provivienda proporcionó a los destechados la manera de intervenir directamente en la solución de los problemas que afectaban su vida cotidiana, de diseñar estrategias de sobrevivencia en la ciudad con recursos no monetarios como el saber ancestral, el apoyo mutuo, el tiempo disponible y la creatividad ${ }^{34}$. También se buscó evitar la soledad moral, creando lazos afectivos y espacios de solidaridad. Para muchos de ellos, pertenecer a la colectividad del barrio significó tener un techo para su familia y simultáneamente construir una identidad barrial. Así con frecuencia el nombre del barrio expresa en cierta medida esa nueva identidad ligada a su militancia política: Policarpa Salavarrieta, Manuela Beltrán, María Cano, Diana Cardona, Primero de Mayo, Comuneros, José Antonio Galán, Atahualpa, Simón Bolívar, Camilo Torres Restrepo, Julio Rincón, Barrio Obrero, Barrio Popular, Isla de Cuba, Salvador Allende, Nuevo Chile, Pablo Neruda, Ciudad Latina, La Libertad, El Porvenir, Nueva Esperanza, Bello Horizonte, etc.

33 Carlos Arango Zuluaga, La lucha por la vivienda...9.

34 Provivienda, Conclusiones de organización y financieras (Bogotá: Archivo Histórico Cenaprov, 1979). 
En la estructura organizativa de cada barrio fue primordial la Asamblea General de Vecinos para la toma de decisiones que afectaran a la comunidad barrial. Esta Asamblea elegía la junta directiva encargada de ejecutar las decisiones colectivas, apoyada en comisiones sectoriales y especiales de trabajo voluntario. Las comisiones sectoriales estaban encargadas de la vigilancia del terreno ocupado por sectores. Las especiales se responsabilizaban de la higiene, la educación, los deportes y las actividades culturales y de solidaridad con otros barrios y sectores sociales ${ }^{35}$.

Con el trabajo de las comisiones en las cuales eran protagonistas las mujeres y los niños, fue posible construir viviendas rodeadas con espacios adecuados, como parques, escuelas y casas culturales. También se organizaron las celebraciones del aniversario del barrio, con la alborada en la cual se prendía el fuego, signo de la victoria de los proviviendistas, festivales, reinados, bazares, concursos y campeonatos. Cargaron agua, buscaron la manera de tener luz en el barrio, corrieron a apagar el fuego en el rancho del vecino, vigilaron de noche y de día, se opusieron a los desalojos. Aportaron tiempo, esfuerzo, voluntad y recursos para mejorar su barrio. Se movilizaron por las reivindicaciones inmediatas de techo y servicios, por las reformas políticas favorables a los destechados, alojaron a los campesinos marchantes y acompañaron a los obreros huelguistas ${ }^{36}$.

Una estrategia efectiva para el éxito de la ocupación fue buscar y obtener la solidaridad de organizaciones sindicales. Con este apoyo lograron consolidarse muchas de las primeras ocupaciones en ciudades diferentes a Bogotá. Este fue el caso del Barrio Primero de Mayo en Valledupar con la asesoría del Sindicato de Oficios Varios. Por su parte, en Girardot 150 familias campesinas que habían invadido en 1961 los terrenos de Barzalosa lograron tras una larga y difícil lucha su adjudicación por el Instituto Colombiano de

35 Provivienda, Reglamento orgánico de los barrios de Provivienda (Bogotá: Archivo Histórico Cenaprov, 1981), 5.

36 Marcela Hernández, Julio Rincón: tres décadas de lucha (Bogotá: Fedes, 2010), 99. 
Reforma Agraria-INCORA, con el apoyo del Sindicato de Trabajadores Agrícolas ${ }^{37}$. También en 1961, los sindicatos de sastres y de trabajadores de la construcción ayudaron a la toma de predios municipales en Neiva para crear el barrio La Libertad. En Ibagué fue el sindicato de ejidatorios quien participó en los años sesenta en las ocupaciones que dieron origen a los barrios Gabinal, Primero de Enero y Antonio José Restrepo. La Federación de Trabajadores del Quindío apoyó a Provivienda en el proceso de obtención de vivienda digna para los ocupantes de las orillas de la vía férrea en Armenia y en la fundación de los barrios Manuela Beltrán y La Libertad.

Es preciso anotar que esta solidaridad fue de doble vía. Los viviendistas también apoyaron las movilizaciones de los trabajadores organizados e incluso promovieron la creación de sindicatos como ocurrió en la ciudad de Pasto, donde el movimiento de destechados dio origen a los sindicatos de mecánicos, de trabajadores de la construcción y más tarde al sindicato de vendedores y trabajadores del comercio ${ }^{38}$.

\section{- Segundo período (1972-1983)}

Es el período de transición organizativa y consolidación de los barrios. Se inicia con la reforma de Estatutos en diciembre de 1971 que prioriza la compra de lotes y la concertación con las autoridades. Es la etapa en la cual los primeros barrios logran su legalización, junto con la instalación de servicios públicos municipales (acueducto, alcantarillado, etc.) y la pavimentación de sus principales vías. En este período, se institucionaliza la idea de hacer que cada barrio de Provivienda logre ser un barrio de nuevo tipo. En este sentido, en Bogotá fue emblemático el barrio Policarpa Salavarrieta, pues representa un modelo de barrio pensado por pobladores comunistas con el propósito de construir un modo de vida contrario al que impera en la sociedad capitalista, con un sentido y una forma diferente de propiedad de la vivienda y con mayor unidad popular. En las entrevistas realizadas

37 Carlos Arango Zuluaga, La lucha por la vivienda...204.

38 Carlos Arango Zuluaga, La lucha por la vivienda...151. 
se menciona cómo en estos barrios se buscó movilizar a sus vecinos en acciones de protección comunitaria; la vigilancia nocturna estaba a cargo de las mujeres que utilizaban como alarma un riel y un martillo, al sonido del cual, en la mitad de la noche, se acudía masivamente a apagar el incendio en el rancho del vecino, disuadir intentos de robo o de desalojo. También, en este período, adelantaron acciones de solidaridad con el movimiento obrero y social en general. Fueron barrios pensados como una fortaleza popular que tenían una política orientada por el Partido Comunista ajena al clientelismo y al gamonalismo de los partidos políticos tradicionales.

Otra característica esencial del barrio de nuevo tipo es que tiene una Casa Cultural, que es un centro social y cultural para las actividades de la comunidad. La Casa Cultural tiene ese nombre para expresar el propósito de Provivienda de elevar el nivel cultural de sus habitantes. Allí se ofrece formación política, se realizan eventos, actividades culturales y recreativas. Es también la sede de las oficinas de la directiva del barrio. Es el eje de la vida barrial. Por eso en el proceso de construcción de cada nuevo barrio, el primer lote que se define en el mejor lugar del asentamiento es para la Casa Cultural.

\section{- Tercer período (1984-1995). Consolidación electoral, iniciativas legislativas y negociación política}

En este período es posible observar cambios sustanciales. En primer lugar, se desiste de las acciones colectivas directas con ocupaciones ilegales de terrenos ociosos, que dieron lugar a los primeros barrios de invasión y son reemplazadas por procedimientos de concertación con el Estado, participación electoral, iniciativas legislativas, compra de terrenos subsidiados y programas de crédito formal de vivienda de interés social. Surgen muchas organizaciones populares y cooperativas dedicadas a la autoconstrucción independientes de Provivienda y relacionadas con la vivienda popular. En primera instancia se encuentran las asociaciones de adjudicatarios de planes oficiales, inquilinos y habitantes de barrios piratas, "subnormales" y normalizados. En segunda, las Cooperativas de ahorro y vivienda con sistemas de crédito 
para sectores medios. Después se encuentran las fundaciones y ONGS que brindan asistencia técnica. En 1985 se intentó generar un movimiento de viviendistas y se realizó un Primer Congreso Unitario de organizaciones populares de vivienda ${ }^{39}$.

En relación con los avances legislativos en materia de vivienda, se pueden mencionar en particular los proyectos de Acuerdo presentados por Mario Upegui, presidente de Provivienda, al Concejo Distrital de Bogotá y que lograron ser aprobados por esa corporación. Entre ellos se encuentran: el Acuerdo 12 de 1984 sobre las obras del Plan Maestro de Alcantarillado del sector sur de la ciudad y en favor de los propietarios de escasos recursos; el Acuerdo 02 de 1988 por el cual se legaliza la ocupación del terreno ocupado por las familias del barrio Yira Castro de Provivienda; el Acuerdo 23 de 1997 sobre ampliación, mantenimiento de la malla vial, acceso y pavimentación de barrios populares y cofinanciación de la Empresa de Acueducto y alcantarillado con la comunidad de la infraestructura sanitaria requerida; el Acuerdo 2 de 1998 para la atención integral de la población desplazada; el Acuerdo 15 de 1998 para promover la organización comunitaria de familias de bajos ingresos y facilitar su acceso al suelo destinado a la vivienda de interés social prioritaria; el Acuerdo 62 de 2002 por el cual se rinde homenaje al prócer cubano José Martí designando con el nombre de "Parque del Pueblo José Martí" al parque barrial ubicado entre carreras 10 y $10 \mathrm{~A}$ y calles 3 y 4 sur del Barrio Policarpa Salavarrieta en la ciudad de Bogotá.

En 1984, las FARC ${ }^{40}$ y el gobierno de Belisario Betancur firman un Acuerdo para iniciar un proceso de negociación del conflicto armado e incorporar a los insurgentes a la vida civil y política legal. Este objetivo pretende llevarse a cabo a través de la creación del Movimiento Político Unión Patriótica (UP), al cual son convocados y llegan a hacer parte de este movimiento diversas organizaciones sociales y sectores democráticos,

39 Rocío Londoño, Una visión de las organizaciones populares en Colombia (Bogotá: Foro, 1994), 22.

40 La guerrilla de las FARC: Fuerzas Armadas Revolucionarias de Colombia. 
donde tienen una participación destacada muchos dirigentes de Provivienda. Con los resultados electorales de 1986 (14 congresistas, 18 diputados y 335 concejales) se inicia el exterminio de la UP, la persecución a los dirigentes de Provivienda y, por lo tanto, el declive de la organización de destechados.

Muchos de los dirigentes de Provivienda que también pertenecieron a la UP, fueron privados de la libertad, desplazados, asesinados o desaparecidos ${ }^{41}$. Entre ellos se encuentran: María Mercedes Usuga, Diana Cardona, Reina Luz Pulgarín, Edilma Moreno, Isabelina Torres, Juana García, Amparo Osorno, Edith Gallego, María Inés Pacheco, Rita Tobón, Luz Mila Torres Lizcano, Mercedes Aldana, Marlén Borja, Alba Sofía Molina, Luz Amparo Jaramillo, María Arango, Hildebrando Lora, Marcelino Blanquicet, Marceliano Medellín, Luis Eduardo Cubides, Bladimiro Escobar, James Barrero, Humberto Morales, Luis Eduardo Yaya, Gabriel Alfredo Briceño, Rubén Lasso, Naum Urrego, Víctor Ochoa, Juan R. Leyva, José Rafael Reyes Malagón, Pedro Nel Jiménez, Epidemio Hernández, Gonzalo Zárate Triana, Humberto Zárate Triana, Eder Enciso Sandoval, Oswal Moreno, Reinaldo Perdomo y muchos otros y otras más. Este plan de exterminio contribuyó en muchos barrios a desarticular los procesos organizativos y a destruir el tejido social originario. Es difícil determinar las dimensiones reales del impacto de la violencia ejercida en contra de la Unión Patriótica, del Partido Comunistas y de Provivienda, con más de 5.000 víctimas por parte de agentes estatales y paraestatales en un proceso de exterminio que se ha prolongado durante casi 30 años.

\section{- Cuarto período (1996-2005)}

En este período puede observarse los estragos del exterminio, por cuanto en la mayoría de los barrios desaparece el tejido social construido por Provivienda. En Colombia este

41 Provivienda, Directorio de Centros de inquilinos. Listado de Centros según Seccionales (Bogotá: Archivo histórico Cenaprov, 1982 y 1983). Corporación Reiniciar, Base de datos de víctimas del genocidio UP. (Bogotá: Archivo Memoria Viva, 2013). 
es un período de predominio paramilitar. El terror surte su efecto y en regiones como Urabá y Meta, con vigorosa presencia de Provivienda, la mayoría de sus afiliados son perseguidos, desplazados y despojados de sus viviendas por los paramilitares. Ante el exterminio de sus dirigentes y el éxodo de muchos fundadores de los barrios, las nuevas directivas de Provivienda buscan sobrevivir y adaptarse a las nuevas políticas públicas. Se adelantan dudosas alianzas temporales para tramitar subsidios gubernamentales y en muchas ocasiones se desatienden las obligaciones contraídas con los afiliados. La dirección administrativa de este período busca distanciarse de las experiencias anteriores, prescindir del carácter de organización social de destechados comunistas estigmatizados y perfilarse como una entidad de asistencia técnica en programas de vivienda y desarrollo urbano. No logra los resultados esperados: la especulación inmobiliaria, las inversiones de alto riesgo con ánimo de lucro y la corrupción administrativa llevaron a Provivienda al borde de la ruina económica. Durante los últimos 9 años, en condiciones críticas, responde poco a poco por las obligaciones contraídas y como el ave Fénix, intenta resurgir de sus cenizas y recuperar sus propósitos fundacionales promoviendo un movimiento de inquilinos y planes de vivienda popular en Tolima y Cundinamarca.

\section{Conclusiones}

Esta historia de Provivienda como protagonista de la colonización popular en Colombia, ilustra cómo sectores sociales víctimas del despojo y del desplazamiento forzado adelantaron estrategias de sobrevivencia inicialmente exitosas, contribuyendo al proceso de urbanización con 500 barrios fundados en 120 municipios a partir de la década del sesenta del siglo XX. Son barrios populares denominados de "nuevo tipo", porque intentan tener una dinámica organizativa y cotidiana basada en la solidaridad y el apoyo mutuo bajo la orientación del Partido Comunista.

A partir de la segunda mitad de la década de los años 80 , sus dirigentes hicieron parte del proyecto de la Unión 
Patriótica, una organización víctima del genocidio político en la que muchos de los viviendistas que hacían parte de ésta son amenazados, perseguidos, desplazados y/o asesinados. En consecuencia, se desarticula el tejido social construido por ellos en sus barrios, al punto de que su historia ha sido desconocida. Por ello, a través de un proceso de Investigación Acción Participativa, se intenta con los fundadores sobrevivientes recuperar la memoria histórica de esta organización social.

¿Por qué en un país como Colombia, donde legalmente está proscrita la pena de muerte, se produce un genocidio político $^{42}$ como crimen de Estado? Responder cabalmente a este interrogante debe ser objeto de múltiples investigaciones. Por el momento, a partir de violentólogos reconocidos académicamente se intenta dar a conocer algunas precisiones:

Francisco Gutiérrez ${ }^{43}$, citando a Darío Echandía afirma que el sistema político colombiano es un "orangután con sacoleva" que se caracteriza por la coexistencia estable entre institucionalidad democrática, permanente represión estatal y estados de excepción con ataques homicidas frente a sectores de la población civil, que el gobierno respectivo puede escoger como blanco porque los considera como potenciales opositores.

Según Marco Palacios, el proceso de violencia pública colombiana se expresa en:

[...] el robo armado y organizado de tierras campesinas que, [...] por muchas décadas, distingue a este país entre aquellos que tienen las mayores concentraciones de la propiedad agraria en el mundo y sus actuales modalidades gansteriles

42 http://www.verdadabierta.com/component/content/article/42-asesinatosselectivos/4390-exterminio-de-la-up- Los magistrados de Justicia y Paz aseguraron que, de acuerdo con el análisis histórico y las pruebas presentadas por la Fiscalía, el exterminio de la Unión Patriótica, UP, fue un genocidio político con la participación y colaboración activa de miembros de la fuerza pública.

43 Francisco Gutiérrez. Antropólogo PHD en Ciencia Política. Ha sido editor de la revista Análisis Político del IEPRI y vicerrector de la Universidad Nacional. El orangután con sacoleva. Democracia y represión en Colombia (1910-2010) (Bogotá: Editorial Pendim Random House, 2014), 12 a 22. 
tienen un antecedente en la segunda ola de violencia, en el cordón cafetero centro-occidental del país. ${ }^{44}$

Consuelo Corredor ${ }^{45}$ explica cómo el Estado colombiano es un Estado privatizado, atrapado entre el conservadurismo político y el liberalismo económico. De cierta manera, el modelo liberal de desarrollo imperante en Colombia basado en la exclusión de amplios sectores de la población, ha profundizado las desigualdades sociales y tiene su complemento en el monopolio del espacio político a través del bipartidismo con la criminalización de la protesta social y la satanización de la oposición política.

En consecuencia, puede concluirse que en el declive de Provivienda observado a partir de la década del 90 del S XX, influyen varios factores:

1. La persecución y exterminio a los dirigentes viviendistas integrantes de la Unión Patriótica y del Partido Comunista influyó en la desarticulación de los procesos organizativos y destruyó el tejido social originario de los barrios de Provivienda.

2. Las ocupaciones ilegales de terrenos ejidales y/o municipales que dieron lugar a los primeros barrios de invasión perdieron peso en las tácticas de lucha de Provivienda, por agotamiento del suelo disponible cercano a las ciudades y por los cambios en la orientación política. Se dio prioridad a actuar dentro de la legalidad, buscando una inclusión plena en su condición de ciudadanos a través de la participación electoral. Sin embargo, esta estrategia no logró conjurar el exterminio al que fueron sometidos.

3. En lo que respecta al ritmo y la cantidad de soluciones de vivienda popular, las urbanizaciones piratas le ganaron la partida a las organizaciones sociales y al Estado. Vieron la

44 Marco Palacios. Doctorado Universidad de Oxford. Fue rector de la Universidad Nacional y es investigador del Colegio de México. Violencia pública en Colombia 1958-2010 (Bogotá: FCE, 2012), 26.

45 Consuelo Corredor, Los límites de la modernización (Bogotá: Cinep, 1997), 21-25. 
oportunidad de comprar terrenos no urbanizados, lotearlos y venderlos de manera ilegal. Estos predios carecían de infraestructura sanitaria, de manera que cada cual tenía que construir su vivienda por sus propios medios. Los urbanizadores piratas tuvieron una mayor capacidad de gestión frente al Estado y mejores posibilidades de acceso a los servicios públicos y a la legalización de los barrios ${ }^{46}$. Sus ofertas ilegales, fueron con frecuencia toleradas por las autoridades porque no estaban dirigidas por organizaciones de izquierda y tenían vínculos con poderosas redes clientelares de los partidos políticos tradicionales y/o de paramilitares ${ }^{47}$.

4. Las relaciones de Provivienda con otras iniciativas de vivienda popular y organizaciones viviendistas ajenas al Partido Comunista no prosperaron. Sus normas estatutarias concebidas bajo el modelo disciplinario de los comunistas, el mantenimiento de una retórica radical y la escasa y lenta renovación de sus propuestas, no la hacen atractiva para muchos colombianos sin vivienda que prefieren acudir a la intermediación de políticos tradicionales con capacidad de gestión ante las autoridades gubernamentales ${ }^{48}$.

5. Reflexionar sobre las experiencias vividas a lo largo de más de cincuenta años en la actual coyuntura de apertura al diálogo entre la insurgencia y el gobierno puede aportar a la comprensión de las causas estructurales del conflicto y contribuir a la construcción de una paz con justicia social.

\section{Fuentes documentales}

Entrevista a Cruz, Celmira, dirigente comunista de Chaparral, nacida en 1930. Cali, 5 de julio de 2011.

46 Francisco Gutiérrez, La ciudad representada (Bogotá: Iepri Universidad Nacional, 1998), 80.

47 Angélica Tamayo, "Barrios de invasión en Bogotá 1961-1974" (Tesis de grado en Historia. Bogotá: Universidad Nacional, 2008); 28.

48 Rocío Londoño. Una visión de las organizaciones...30. 
Entrevista a Dorado, Jesús María, maestro liberal del Cauca, nacido en 1920. Bogotá, 10 de febrero de 2013.

Entrevista a Borray, Anita, fundadora del barrio Primero de Mayo en Valledupar, nacida en Cundinamarca en 1935. Valledupar, 7 de enero de 2011.

Entrevista a Upegui, Mario, dirigente de Provivienda y Concejal de Bogotá. Bogotá, 2 de octubre de 2011.

Entrevista a Quintero, Guzmán, fundador del Barrio Fundadores de Valledupar. Valledupar, 10 de enero de 2011.

Entrevista a Martínez, Vicente, sindicalista fundador del barrio Primero de Mayo en Valledupar. Valledupar, Enero 25 de 2011.

Entrevista a Jerez, Luis, presidente nacional de Provivienda en 2012. Bogotá, 20 de febrero de 2012.

Provivienda. Informe a la III Asamblea Nacional. Bogotá: Archivo Histórico Cenaprov, 1963.

Informe a la V Asamblea Nacional. Bogotá: Archivo Histórico Cenaprov, 1967.

. Estatutos de Cenaprov. Bogotá: Archivo Histórico Cenaprov 1971.

. Conclusiones de organización y financieras. Bogotá: Archivo Histórico Cenaprov, 1979.

.Plataforma de lucha de la Central Nacional Provivienda. Archivo Histórico Cenaprov, 1979.

- Reglamento orgánico de los barrios de Provivienda. Bogotá: Archivo Histórico Cenaprov, 1981.

.Listado de Centros según Seccionales. Bogotá: Archivo Histórico Cenaprov, 1982.

Directorio de Centros de inquilinos. Bogotá: Archivo Histórico Cenaprov, 1983. 


\section{Bibliografía}

Aprile-Gniset, Jacques. La crónica de Villarrica. Bogotá: Ediciones Ilsa, 1991.

. La ciudad colombiana. Bogotá: Banco Popular, 1992.

."Memorias del destierro y del exilio". En: Cátedra Jorge

Eliécer Gaitán. Bogotá: Universidad Nacional, 2007.

Arango Zuluaga, Carlos. La lucha por la vivienda en Colombia. Bogotá: Ecoe, 1985.

Bergquist, Charles. Café y conflicto en Colombia, 1886-1910. Medellín: FAES, 1981.

Buenaventura, Nicolás. Cartilla Básica de Educación Provivienda. Bogotá: Ceis, 1981. . ¿Qué pasó camarada? Bogotá: Apertura, 1992.

Corporación Reiniciar. La paz frustrada en tierra firme. Bogotá: D'vinni S.A, 2009.

Corredor, Consuelo. Los límites de la modernización. Bogotá: Cinep, 1997.

Gutiérrez, Francisco. La ciudad representada. Bogotá: Iepri Universidad Nacional, 1998.

Hernández, Marcela. Julio Rincón: tres décadas de lucha. Bogotá: Fedes, 2010.

Inurbe. Evaluación de las organizaciones de vivienda popular. Bogotá, 1983.

Jaramillo, Samuel. Organización popular y desarrollo urbano. Bogotá: U. Externado, 1997.

Londoño, Rocío. Una visión de las organizaciones populares en Colombia. Bogotá: Foro, 1994.

. Juan de la Cruz Varela. Sociedad y política en Sumapaz. Bogotá: FCH, 2012. 
Oviedo, Álvaro. Memoria y luchas urbanas. Bogotá: Ed. Izquierda viva, 2012.

Palacios, Marco. Violencia pública en Colombia 1958-2010. Bogotá: FCE, 2012.

Sánchez, Gonzalo. Guerra y política en la sociedad colombiana. Bogotá: Ancora, 2008.

Sánchez, Lina. "Migración forzada y urbanización en Colombia”. En: Procesos Urbanos Informales. Bogotá: Universidad Nacional, 2007.

Tamayo, Angélica. "Barrios de invasión en Bogotá 1961-1974". (Tesis de grado en Historia. Universidad Nacional. Bogotá. 2008).

Torres, Alfonso. La ciudad en la sombra. Bogotá, Cinep, 1993.

Urrea, Fernando y Murillo, Fernando. "Dinámica del poblamiento y algunas características de los asentamientos populares con población afrocolombiana en el oriente de Cali”. Ponencia presentada al Observatorio Socio-político y Cultural sobre Desplazados, migraciones internas y reestructuraciones territoriales. Bogotá: FCH Universidad Nacional de Colombia, 1999.

\section{Citar este artículo:}

María Elvira Naranjo Botero, "Provivienda: protagonista de la colonización popular en Colombia", Revista Historia y Memoria No. 09 (julio-diciembre, 2014): 89-118. 